\title{
A política nacional de saúde mental brasileira: breve análise estrutural
}

\author{
Brazilian National Mental Health Policy: brief structural analysis
}

Sara Mexko*

Silvio José Benelli**

\begin{abstract}
Resumo - Este ensaio visa problematizar a política nacional de saúde mental brasileira por meio de uma análise estrutural que considere os desdobramentos políticos nesse campo. Como aporte teórico-metodológico, recorre-se ao conceito de hegemonia, assim como a conceituação paradigmática de Costa-Rosa. A Lei da Reforma Psiquiátrica, fruto do processo de luta, ao redirecionar o modo de atenção do tratamento asilar para o territorial abriu uma importante brecha para a superação do paradigma psiquiátrico hospitalocêntrico medicalizador pelo paradigma psicossocial. Todavia, na última década a política de saúde mental tem sofrido um conjunto de retrocessos por meio de resoluções e portarias, trazendo de volta obsoletos estabelecimentos e antigas práticas. $\mathrm{O}$ paradigma psiquiátrico não somente continua a ser hegemônico como também tem ampliado sua hegemonia.
\end{abstract}

Palavras-chave: política de saúde; saúde mental; reforma psiquiátrica; hegemonia; paradigma.

\begin{abstract}
This essay aims to problematize the Brazilian National Mental Health Policy through a structural analysis that take into consideration the political developments in this field. As theoreticalmethodological references, the concept of Hegemony and CostaRosa's paradigmatic conceptualization have been chosen. The Psychiatric Reform Law, the result of a struggle process that redirected the care mode from asylum to territorial treatment. Thus, it has opened an important gap for the Psychosocial Paradigm to replace the hospitalcentric medicalized Psychiatric Paradigm. However, in the last decade, the Mental Health Policy has suffered a series of regressions through resolutions and ordinances, bringing back obsolete establishments and old practices. The Psychiatric Paradigm not only continues to be hegemonic, but it has also expanded its hegemony.

Keywords: health policy; mental health; psychiatric reform; hegemony; paradigm.
\end{abstract}

\footnotetext{
* Psicóloga do Centro de Atenção Psicossocial I. Especialista em Saúde Mental e Atenção Psicossocial. Mestre e doutora em Psicologia pela Universidade Estadual Paulista (Unesp), Faculdade de Ciências e Letras, Assis, SP. E-mail: saramexko@gmail.com. ORCID: https://orcid.org/0000-0002-1617-0974.

** Psicólogo e mestre em Psicologia pela Universidade Estadual Paulista (Unesp), Faculdade de Ciências e Letras, Assis, SP. Doutor em Psicologia Social pelo Instituto de Psicologia, USP, São Paulo. Professor assistente no Depto. de Psicologia Clínica e no Programa de Pós-Graduação em Psicologia da Universidade Estadual Paulista (Unesp), Faculdade de Ciências e Letras, Assis, SP. E-mail: silvio.benelli@unesp.br. ORCID: https://orcid.org/0000-0001-8394-9331.
} 
No Brasil, a Atenção ${ }^{1}$ em Saúde Mental é ofertada por meio do Sistema Único de Saúde (SUS) e está institucionalizada pela Política Nacional de Saúde Mental (PNSM). Essa política é amparada pela Lei no 10.216/ 2001 (BRASIL, 2001) e orientada pelas diretrizes da Reforma Psiquiátrica brasileira (RPb). Os atendimentos são ofertados em diversos estabelecimentos que compõem a Rede de Atenção Psicossocial (Raps). A Raps, instituída em 2011 (BRASIL, 2011) e reformulada em 2013, tem por finalidade a criação, articulação e organização dos estabelecimentos que ofertam tratamento na área da Saúde Mental. A Lei da Reforma Psiquiátrica (BRASIL, 2001) abriu uma importante brecha para a mudança do modelo² de Atenção em Saúde Mental por meio da superação do Paradigma Psiquiátrico Hospitalocêntrico Medicalizador (PPHM), sendo a Reforma Psiquiátrica um caminho em direção ao Paradigma Psicossocial (PPS) (COSTA-ROSA, 2013).

Passados 20 anos da homologação da Lei da Reforma Psiquiátrica (BRASIL, 2001), nos perguntamos sobre sua construção, quais os avanços e retrocessos aconteceram em sua efetivação e quais questões políticas, econômicas e sociais participaram para que fosse assim. O presente ensaio busca analisar o campo da Saúde Mental brasileira e sua consistência institucional enquanto política pública pertencente ao SUS. Mais especificamente, propomos realizar uma análise lógico-estrutural que leve em conta os desdobramentos políticos e as possibilidades dessa política no cenário atual. Para tal, nos serviremos da leitura gramsciana sobre Hegemonia e da Análise Institucional em sua vertente francesa (LOURAU, 2014; BAREMBLITT, 2012).

\section{A instituição Saúde Mental e o Processo de Estratégia de Hegemonia: introduzindo alguns conceitos}

No contexto de certa sociedade e, em cada bloco histórico, as atividades humanas são permeabilizadas pelas instituições que, segundo Baremblitt (2012), têm por função realizar a regulação das relações sociais. Para a Análise Institucional, uma instituição é uma "forma universal, ou considerada como tal" (LOURAU, 2014, p. 15). Instituição também pode ser entendida como "conjunto articulado de saberes (ideologias) e práticas (formas de intervenção normatizadora na vida dos diferentes grupos e classes

\footnotetext{
${ }^{1}$ Seguindo Costa-Rosa (2013), grafamos o termo Atenção com inicial maiúscula para nos referirmos ao conjunto de ações executadas no campo da Saúde Mental que são nomeadas de cuidado, promoção, tratamento e atenção. 2 O modelo assistencial é a forma de organização/combinação de tecnologias (materiais e não materiais) utilizadas no processo de oferta da atenção em saúde (PAIM, 2001; TEIXEIRA; PAIM; VILASBOAS, 1998).
} 


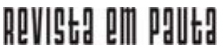

\} A POLÍTICA NACIONAL - MEXKO, S.; BENELLI, S. J. \}

DOI: $10.12957 /$ REP.2022.63480

sociais)" (LUZ, 1979, p. 30) com efeitos fundamentalmente políticos. Compreendendo as instituições como malhas concretas das formações sociais, Luz (1979) demarca, nesse sentido, que elas são lugares privilegiados de luta política. Como as instituições articulam um conjunto de interesses, acontecem disputas entre visões de mundo e de projetos alternativos e concorrentes de sociedade; deste modo, há uma "estratégia de luta - não necessariamente aberta - entre grupos e classes sociais constitutivos destas instituições e inseridos em um bloco histórico" (LUZ, 1979, p. 31). De acordo com Luz (1979), a hegemonia de classe está centrada nas instituições sociais.

Gruppi (1978) define a hegemonia, para Gramsci, enquanto o domínio de uma classe (polo) social sobre todo o conjunto da sociedade a totalidade das classes e grupos sociais -, operada por um poder ideológico, cultural, social, político e econômico. Para Costa-Rosa (1987, p. 34), "a hegemonia traduz-se pela primazia ideológica e econômica de uma classe e prolonga-se, normalmente, através da hegemonia política". A hegemonia não consiste em um sistema formal fechado, bem como não é completamente homogênea e articulada; trata-se de um processo móvel que abarca não apenas a estrutura macroeconômica e a organização política da sociedade, mas também influencia os planos culturais e ideológicos. Nesse sentido, a hegemonia não tem o sentido somente de domínio de uma classe social em relação às demais classes, mas a capacidade das classes na elaboração de visão de mundo.

Luz (1979) propõe uma interpretação dinâmica do conceito de hegemonia: trata-se de um processo e prática contraditória, uma vez que institui como universal aquilo que é essencialmente particular. O conceito gramsciano de Processo de Estratégia de Hegemonia (PEH), utilizado na análise política das instituições, permite analisar o jogo de forças que compõem as instituições e nelas se atualizam, possibilitando desvelar como fatores estruturais interferem nos elementos conjunturais e locais.

Conforme Costa-Rosa (2013), o PEH envolve um conjugado de práticas, relacionadas à estratégia e à tática, que tem por finalidade manter a formação social, seja uma instituição ou a própria sociedade, em equilíbrio dinâmico, quanto aos interesses dominantes e subordinados. Em virtude de as realidades serem sempre segmentares e contraditórias, no que diz respeito a interesses e a visões de mundo que se atualizam nesse processo, essa segmentaridade tende a ser polarizada. Nesse processo, é possível demarcar a existência de dois polos de um mesmo contínuo em oposição dialética, o polo dominante e o polo subordinado, e um amplo conjunto de saberes e práticas que variam entre diferentes, alternativos e contraditórios.

Do lado dominante, constituído por uma pequena parcela da população, há um conjunto de práticas de efeitos ideológicos e repressivos, assim como um conjunto de concessões táticas que, posteriormente, podem 
ser recuperadas. Do lado subordinado, existe um conjunto de práticas que estão em consonância com o polo dominante e são reproduzidas devido à dominância material e ideológica desse polo. Todavia, o polo subordinado produz reivindicações e práticas alternativas, ora ativas e ora passivas, que algumas vezes podem aspirar à elaboração de uma hegemonia alternativa à dominante - de tornar hegemônicos os interesses socialmente subordinados.

Segundo Costa-Rosa (2013), Gramsci considera que há duas maneiras pelas quais o polo dominante exerce seu poder, isto é, realiza o controle da sociedade civil por intermédio do Estado: pelo PEH ou por ditadura. Para realizar esse processo e manter o controle para si, pela obtenção do consentimento das massas, o polo dominante se serve de um conjunto de instituições civis propagadoras de cultura, denominadas por Althusser (1980) de Aparelhos Ideológicos de Estado (AIE), cuja função é orientar os interesses e as necessidades do polo subordinado. Esses AIE funcionam "[...] de um modo massivamente prevalente pela ideologia, embora funcionando secundariamente pela repressão, mesmo que no limite, mas apenas no limite, esta seja bastante atenuada, dissimulada ou até simbólica" (ALTHUSSER, 1980, p. 47). Apenas quando a dominação ideológica perde sua potência e eficácia, não dando conta de manter em equilíbrio interesses contraditórios, é que a repressão é largamente utilizada, entrando em cena os Aparelhos Repressivos de Estado (ALTHUSSER, 1980).

Em momentos de acirramento das contradições, da luta de classes, quando fica mais evidente o distanciamento entre os representantes e os representados, e o polo subordinado apresenta reivindicações que constituem uma revolução popular, acontece a "crise de hegemonia" ou crise de representação. Nesses períodos de crise de representação, aparece outra forma de regime político: a ditadura. No regime ditatorial, a classe social dominante irá fazer uso, majoritariamente, dos Aparelhos Repressivos de Estado, ainda que os Aparelhos Ideológicos não deixem de também realizar sua função.

Há ainda a possibilidade de os dois regimes atuarem juntos, mesmo que algum deles tenha prevalência. No Modo Capitalista de Produção (MCP), para sua própria perpetuação, é imprescindível que o Estado participe ativamente da organização da sociedade civil por meio das políticas públicas. Essas constituem os meios usados pelo Estado para a manutenção do status quo. Por meio dessas políticas, são garantidas tanto as condições político-ideológicas quanto econômicas de reprodução do sistema hegemônico e seu modo de produção (GOTO, 2018). Conforme Costa-Rosa (2013), o caso da instituição Saúde Mental (e seus estabelecimentos) ilustra bem o $\mathrm{PEH}$, pois nelas é possível visualizar os efeitos de uma real luta pela hegemonia das visões culturais, ideológicas, teórico-técnicas e éticas. O PEH possibilita fazer a análise do jogo de forças, contrapondo os aspectos do PPHM aos do PPS. 


\section{A formulação da Política Nacional de Saúde Mental no governo federal: incidências do Modo Capitalista de Produção}

O Projeto de Lei $n^{0}$ 3.657/89, apresentado pelo deputado Paulo Delgado (PT-MG), era bastante simples e continha apenas três artigos estruturantes. O primeiro artigo impedia que o poder público contratasse ou construísse novos hospitais psiquiátricos. O segundo tratava do direcionamento do dinheiro público para a criação de recursos não manicomiais para atendimento aos sujeitos do sofrimento. Já o terceiro obrigava que as internações compulsórias fossem comunicadas à autoridade judiciária. Esse projeto foi aprovado na Câmara dos Deputados, mas não foi aprovado diretamente no Senado. Como resultado do processo de mobilização por parte do Movimento da Reforma Psiquiátrica - que englobava os militantes do Movimento da Luta Antimanicomial - em articulação com os movimentos sociais, antes mesmo da Reforma Psiquiátrica ser aprovada e sancionada, entre 1990 e 1995 foram criados quase 100 estabelecimentos de tratamento no território (PITTA, 2011).

A partir da década de 1990, um conjunto de portarias do Ministério da Saúde (MS) institucionalizou a PNSM: a Portaria no 189, de 11 de dezembro de 1991 (BRASIL, 1991) e a Portaria no 224, de 29 de janeiro de 1992 (BRASIL, 1992), deram condições de o SUS financiar programas de assistência no território, como os Núcleos de Atenção Psicossocial (Naps), entre outros. Essa segunda portaria definiu as normas de funcionamento dos Centros de Atenção Psicossocial (Caps), especificando seus tipos e atribuições. A Portaria no 106/2000 (BRASIL, 2000) criou os Serviços Residenciais Terapêuticos para acolher pessoas com longo tempo de internação em hospitais psiquiátricos que não possuíam mais laços familiares e suporte social.

A pressão política do setor privado que lucrava com o modelo manicomial funcionou como importante obstáculo à Reforma Psiquiátrica, gerando alterações no texto do projeto de lei e na demora para sua aprovação. Somente depois de onze 11 anos o projeto foi aprovado no Senado em 1999, após pressão da Corte Interamericana de Direitos Humanos em decorrência do caso Daniel Ximenes, e, depois de muitos substitutivos, por meio de uma articulação entre o deputado proponente, o MS e o movimento antimanicomial, além de ter retornado para a Câmara enquanto projeto substitutivo, onde passou por diversas negociações. Nesse percurso, o primeiro artigo do projeto original foi excluído, permitindo que hospitais psiquiátricos particulares e filantrópicos recebessem recursos governamentais para a internação de pacientes.

No artigo $2^{\circ}$, que trata dos direitos no atendimento, consta "IX ser tratada, preferencialmente, em serviços comunitários de saúde mental" (BRASIL, 2001). O termo "preferencialmente" deixou a porta aberta para que as internações continuassem existindo como prática comum. Em contrapartida, foram incluídas outras reivindicações do movimento como, por 
exemplo, a oferta de tratamento em serviços comunitários visando à inserção social do sujeito em seu meio e a indicação da criação de política específica para os pacientes com longa internação e/ou grave dependência institucional. Dada a forma como se processou a RPb, ela se configurou enquanto uma revolução passiva.

Revolução passiva diz respeito a uma reforma que acolhe uma determinada parte das exigências que vieram de baixo, realizada de cima para baixo, construída sem a participação da população. Esta compreende a presença de dois momentos: restauração e renovação. Na restauração, ocorre uma reação conservadora diante de uma possível transformação efetiva e radical, cuja origem são as classes populares. Esse aspecto restaurador não invalida o fato de haver também modificações efetivas. No momento de renovação, existe o atendimento de algumas demandas populares, por meio de concessões das camadas dominantes, com a finalidade de acalmar as massas.

Desse modo, são realizadas algumas modificações, contudo, o aspecto restaurador também está presente (COUTINHO, 2010). Nesse sentido, na renovação foram atendidas as reivindicações dos movimentos por meio da criação da Lei da Reforma Psiquiátrica (BRASIL, 2001), que reconfigurou o modelo de tratamento da hospitalização/manicomialização para o tratamento no território, com a criação de estabelecimentos para tal, sem, no entanto, excluir o hospital psiquiátrico como um dos componentes da rede assistencial de Saúde. Foi realizado um recorte da demanda social de desinstitucionalização, constituindo-se, sobremaneira, como desospitalização. Tratou-se de uma concessão tática do polo dominante com alguns aspectos de restauração, visando manter seu domínio e obter o consenso por parte do polo subordinado, uma vez que as internações hospitalares não deixaram de existir e a psiquiatria teria ampliado seu espaço de atuação ao estar diretamente vinculada aos estabelecimentos de tratamento no território, expandindo, dessa forma, exponencialmente a medicalização, logo, o lucro da indústria farmacêutica.

O transformismo é outro conceito de matriz gramsciana que pode auxiliar na compreensão desse processo histórico no campo da Saúde Mental. O transformismo é um processo que, "através da cooptação de lideranças políticas e culturais de classes subalternas, busca excluí-las de todo efetivo protagonismo nos processos de transformação social" (COUTINHO, 2010, p. 38). Amarante (1998) refere que, a partir de 1985, ativistas do Movimento dos Trabalhadores de Saúde Mental ocuparam postos de chefia de programas estaduais e municipais de Saúde Mental e a direção de importantes unidades hospitalares públicas.

Yasui (2006) demarca que, no início desse novo milênio, apesar da RPb ter se fortalecido como política pública, com o MS enquanto indutorchefe tanto do ritmo como dos rumos desse processo, houve um afastamento com relação aos movimentos sociais, produzindo um deslocamento da 


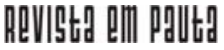

\} A POLÍTICA NACIONAL - MEXKO, S.; BENELLI, S. J. \}

DOI: $10.12957 / R E P .2022 .63480$

luta para o interior do aparelho estatal. Pitta (2011) assinala uma contradição no processo de ocupação de postos de chefia: depositou-se esperanças nas lideranças que ocuparam cargos de gestão, mas em seguida essas foram isoladas da realidade concreta dos locais da práxis efetiva e, além disso, os líderes na gestão - ao que parece, por falta de leitura dialética - passaram a ver as críticas dos movimentos sociais como ataque ao processo de RPb. Em virtude disso, o efeito da ocupação de cargos estratégicos a nível federal e municipal foi, por um lado, um avanço na formulação das estratégias e políticas de Saúde Mental, mas, por outro, representou um silenciamento das críticas ao governo. As ações ficaram centradas em garantir o acesso da população aos serviços substitutivos, mesmo que esses ainda trabalhassem articulados com o Hospital Psiquiátrico (GOTO, 2018).

Por meio do conceito de revolução passiva, pudemos compreender que o modelo manicomial fez um conjunto de concessões às reivindicações dos movimentos pela Reforma Psiquiátrica. A Reforma Psiquiátrica brasileira proporcionou certos avanços no tratamento em Saúde Mental, mas sem alterar totalmente a sua lógica paradigmática, inclusive trazendo elementos reacionários (restauração). Concordamos com Goto (2018, p. 44) quando demarca que "a substituição do manicômio arquitetônico pelo manicômio químico, além da reprodução das relações sociais no interior dos equipamentos que deveriam ser substitutivos ao Hospital Psiquiátrico, torna a $\mathrm{RPb}$ uma reforma cosmética de grandes proporções". A Reforma Psiquiátrica, e mais particularmente a Atenção Psicossocial, ocorreram nas brechas do paradigma dominante (PPMH) (COSTA-ROSA, 2013; GOTO, 2018).

Em 2002, o MS publicou a Portaria no 336/02 (BRASIL, 2002), propondo um novo modelo de assistência. Nela, definiu o Caps como estabelecimento de Atenção diária e territorial, criando as três modalidades (Caps I, II e III), ao passo que especifica esse estabelecimento como articulador das ações de Saúde Mental dos municípios. Suas responsabilidades são: atividades de supervisão de unidades hospitalares psiquiátricas, supervisão e capacitação de equipes da Atenção básica e organização da demanda e da rede de cuidados. Uma observação do PEH, no qual se opõem os dois paradigmas de Atenção (PPHM e PPS), permite compreender que a criação dos Caps foi uma resposta tática do setor dominante (operado por meio do Estado) às reivindicações dos setores subordinados (representados pelo movimento da Reforma Psiquiátrica). Sua institucionalização, por meio das portarias, o tornou pouco diferenciado em termos teóricos, técnicos e ideológicos dos outros estabelecimentos, tais como o Hospital-Dia e o Hospital Psiquiátrico. Yasui (2006) pontua a rigidez produzida pela institucionalização, pois não houve mais abertura para experiências inventivas que não seguissem os parâmetros das portarias, o que se configura como uma ironia tendo em consideração que as mesmas portarias foram inspiradas nas primeiras experiências de Caps e Naps, ambas nascidas de movimentos de invenção. 


\section{A Reforma Psiquiátrica institucionalizada: o avanço, a estagnação e alguns recuos}

Coutinho (2010), inspirado no conceito gramsciano de pequena política, elaborou o conceito de hegemonia da pequena política para esclarecer como se apresenta a hegemonia no neoliberalismo. A grande política diz respeito a questões relacionadas à permanência de estruturas orgânicoeconômico-sociais, à criação de novos Estados, enquanto a pequena política se relaciona com as questões parciais e do cotidiano que aparecem em uma estrutura já constituída. Para o autor, no neoliberalismo a hegemonia de classes se manifesta por meio da exclusão da grande política, ou seja, a hegemonia se realiza com a redução das questões à pequena política. A luta por hegemonia não se dá apenas quando há o enfrentamento de grandes projetos de sociedade. Quando um conjunto de valores e de crenças ganha força no senso comum e orienta o modo de pensar e de agir das grandes massas, mesmo que elas não tenham plena consciência disso, é estabelecida uma relação de hegemonia. Existe hegemonia quando grupos sociais aderem consensualmente a determinados valores.

A hegemonia da pequena política se fundamenta principalmente no consenso passivo, isto é, quando não existe a atuação participativa das massas (partidos, movimentos sociais etc.), mas uma aceitação passiva do existente como sendo natural. Mais especificamente, quando as ideias e os valores das classes dominantes são transformados em senso comum das grandes massas, inclusive das classes mais subalternas. Em contextos no qual se forma a ideia de que a política se resume a disputas de poder entre diferentes segmentos da elite, convergindo na aceitação disso que existe como natural, estamos diante da hegemonia da pequena política. Coutinho (2010, p. 32) destaca que esta hegemonia acontece "quando a política deixa de ser pensada como arena de luta por diferentes propostas da sociedade e passa, portanto, a ser vista como um terreno alheio à vida cotidiana dos indivíduos, como simples administração do existente".

Durante as gestões petistas dos anos de 2003 a 2016, ocorreram avanços e retrocessos na implantação e fortalecimento da Raps. Com a eleição de Luiz Inácio Lula da Silva em 2003, por meio da ocupação de cargos de gestão por militantes no MS, assim como nos municípios, houve uma oportunidade de avanços na Reforma Psiquiátrica em direção à Atenção Psicossocial. Nesse mesmo ano, ainda em janeiro, foi aprovado e sancionado o Projeto de Lei no 1152/03 (BRASIL, 2003), que instituiu o auxílio reabilitação psicossocial para sujeitos do sofrimento internados em hospitais psiquiátricos que voltassem a viver com a família, sendo parte integrante do programa "De volta para a casa".

O conceito de hegemonia às avessas (OLIVEIRA, 2010) também nos auxilia a compreender o período do Partido dos Trabalhadores à frente do governo do país. Nesse modo de hegemonia, típica do mundo glo- 


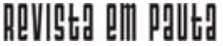

\} A POLÍTICA NACIONAL - MEXKO, S.; BENELLI, S. J.

DOI: $10.12957 /$ REP.2022.63480

balizado, as classes dominantes consentem em ser politicamente conduzidas pelas classes dominadas, contanto que a forma de exploração capitalista não seja questionada. Enquanto a direção moral da sociedade é dada pelas classes dominantes - com vitórias intelectuais e políticas -, há o fortalecimento das relações sociais de exploração, isto é, a dominação burguesa amplia sua força.

Em virtude de o governo federal adotar uma política econômica de cunho neoliberal, privilegiando o capital financeiro, em 2004 recursos orçamentários foram retirados da Saúde para o custeio da dívida pública (MARQUES; MENDES, 2007). Apesar dos cortes no SUS, na Saúde Mental houve um aumento exponencial na abertura de Caps, que passou de 500 em 2003 para 1742 em 2011. O aumento dos Caps, contudo, não significou uma mudança de paradigma, uma vez que muitos estabelecimentos funcionavam a partir de uma lógica próxima à manicomial e em parceria com os Hospitais Psiquiátricos, para onde encaminhavam os sujeitos com sofrimento psíquico mais intenso. Além disso, não houve o fechamento dos manicômios conforme se esperava; entretanto, dado o transformismo operado, o movimento social perdeu força e entendeu o questionamento das medidas governamentais como não estratégicas, silenciando suas críticas.

Entre 2001 e 2009, o montante investido na Saúde Mental subiu $51,2 \%$, tendo sido de 1.003 bilhões de reais em 2001 e de 1.599 ,9 bilhões em 2009. Apesar desses avanços, no ano de 2010 o relatório da $4^{a}$ Conferência Nacional de Saúde Mental - Intersetorial (BRASIL, 2010) já apontava para o cenário de embate entre o movimento em defesa da RPb e a representação de parte dos médicos psiquiatras com exigências corporativistas, "com nova ênfase no modelo biomédico e forte e implícita campanha contra a reforma psiquiátrica" (SISTEMA ÚNICO DE SAÚDE, 2010, p. 8). Além disso, diversos municípios terceirizaram a gestão de Caps por meio da contratação de Organizações Sociais, precarizando os vínculos trabaIhistas, sucateando o serviço ofertado e transferindo dinheiro público para a iniciativa privada.

Dilma Rousseff assumiu a presidência do país em 2011, num período de recessão econômica mundial que também atingiu a economia nacional. No mesmo ano, a Portaria ${ }^{\circ} 3088 / 2011$ (BRASIL, 2011) instituiu a Rede de Atenção Psicossocial (Raps), republicada em 2013, que ampliou e articulou pontos de atenção para atendimento de sujeitos em sofrimento psíquico. No ano seguinte foi aprovada a Portaria no 131/2012 (BRASIL, 2012), que destinava recursos do MS, sob gestão de Alexandre Rocha dos Santos Padilha, para Comunidades Terapêuticas (CT), na contra-mão do modelo de tratamento que vinha sendo construído sob o horizonte ético dos ideais da $\mathrm{RPb}$. As CT estão na contramão da RPb por retirar o sujeito do convívio social, tal como faz os manicômios, por seu tratamento estar baseado na abstinência, contrariando a política de redução de danos, e pelo desrespeito à laicidade, uma vez que essas comunidades geralmente possuem práticas religiosas. 
A partir de 2013, houve retração no orçamento destinado à PNSM, que caiu para 2,1\% e em 2016 diminuiu para apenas 1,6\%. Esse subfinanciamento compromete a eficiência da RPb por impactar tanto na expansão da rede de serviços como na deterioração dos estabelecimentos que já existiam. No segundo governo de Dilma Rousseff (2015-2016), alterou-se a correlação de forças políticas no governo federal e os interesses dos grupos aliados ao manicômio adquiriram ênfase na política oficial do MS. A nomeação de Marcelo Castro como ministro da saúde contribuiu para que os setores conservadores ampliassem o ataque à PNSM e a Associação Brasileira de Psiquiatria ganhasse espaço na gestão pública (CAPUTO et al., 2020).

Em 2015, a nomeação do ex-diretor técnico do manicômio Casa de Saúde Dr. Eiras (RJ) e defensor do modelo manicomial, Valencius Wurch Duarte Filho, para a Coordenação Geral de Saúde Mental, Álcool e outras Drogas (CGMAD) - em troca de apoio político do PMDB -, já anunciava claramente os primeiros sinais de recuos. Para Caputo et al. (2019), esse foi um momento de ruptura ideológica, pois até então os nomeados para a CGMAD eram alinhados aos princípios e diretrizes da $\mathrm{RPb}$. Na tentativa de impedir sua posse, isto é, trabalhadores, estudantes e simpatizantes da RPb ocuparam a sala da coordenação no MS por 123 dias. Além disso, houve manifestações pelo país, com apoio de diversos setores, como artistas, professores e políticos, porém esse ato de resistência não conseguiu barrar a troca de coordenação. Vemos aqui um movimento de restauração das concessões feitas na criação da lei e das portarias subsequentes que institucionalizaram importantes aspectos da RPb.

\section{A contrarreforma psiquiátrica e o cenário atual no ano de 2020}

Ainda durante as gestões petistas, ocorreu a crise de hegemonia (ou crise de representação), ou seja, quando existe um distanciamento cada vez maior entre representantes (partidos) e aqueles que dizem ou deveriam representar (população), o que produz uma situação delicada e perigosa por abrir espaço para soluções de três modalidades possíveis e diferentes: com o uso da força, por meio da atividade de poderes ocultos, ou, ainda, com a emergência de homens carismáticos ou providenciais (BIANCHI, 2017). Como consequência, em 2016 houve o impeachment de Dilma Rousseff e a presidência ficou a cargo de Michel Miguel Elias Temer, do PMDB (atual MDB), que "hoje não passa de uma federação de diversificados interesses pessoais e regionais" (COUTINHO, 2010, p. 42).

Durante seu governo, em 2017, o MS aprovou a Resolução no 32 (BRASIL, 2017a), que produziu mudanças na PNSM, na contramão do que diz a própria lei da $\mathrm{RPb}$. Essa suposta nova política, que nada mais é do que o retorno da velha, realinhou-se com a lógica manicomial ao resolver introduzir na Raps o Hospital Psiquiátrico e reajustar o valor das diárias 


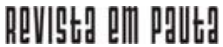

\} A POLITICA NACIONAL - MEXKO, S.; BENELLI, S. J. \}

DOI: $10.12957 / R E P .2022 .63480$

para as internações em hospitais especializados (leia-se psiquiátricos). Com isso, favoreceu a iniciativa privada e obrigou que os dispositivos territoriais passassem a disputar recursos públicos com estabelecimentos privados, trazendo de volta a "indústria da loucura".

O MS publicou, em 21 de dezembro de 2017, a Portaria no 3.588 (BRASIL, 2017b), que alterou as diretrizes da PNSM. Essa portaria efetuou a desestruturação da lógica organizativa da Raps por meio do retorno de serviços obsoletos, como por exemplo as antigas unidades ambulatoriais especializadas, que poderão voltar a realizar práticas reducionistas e servir para ampliação da compra e distribuição de psicofármacos, reforçando a medicalização da vida e do sofrimento. Já em 2018, foi publicada a Portaria no 2.434 (BRASIL, 2018), que concedeu um significativo aumento na tabela de preços das internações em Hospitais Psiquiátricos, gerando com isso um desestímulo à promoção de práticas de desinternação e de desinstitucionalização.

Nos últimos cinco anos, estamos em um tempo em que não existe espaço para o aprofundamento de direitos sociais e que o próprio Estado está produzindo a supressão de direitos conquistados pela luta da classe trabalhadora, e, "por conseguinte, de restauração plena da economia política do capital" (COUTINHO, 2010, p. 37). Por meio do conceito de contrarreforma, podemos compreender não somente a retirada de direitos dos trabalhadores, como também os retrocessos na PNSM. O que caracteriza a contrarreforma, para Coutinho (2010, p. 38), "não é a completa ausência do novo, mas a enorme preponderância da conservação (ou mesmo da restauração) em face das eventuais e tímidas novidades".

Ainda em 2018, formou-se a Frente Parlamentar Mista em defesa da Nova Política de Saúde Mental e Assistência Hospitalar, movimento que tem apoio principalmente das entidades representativas do setor hospitalar, fortalecendo a hegemonia manicomial. O documento que subsidiava esse grupo, de cunho contrarreformista, era iniciativa da Federação Brasileira de Hospitais, representante da rede de saúde privada. O modelo manicomial ganhou espaço novamente, não apenas com representantes dentro do MS, como também no congresso.

Com a eleição de Jair Messias Bolsonaro à presidência, no final de 2018, acentuou-se o processo de contrarreforma. No campo da Saúde Mental, isso se tornou emblemático por meio da Nota técnica Técnica no 11/2019-CGMAD/Dapes/SAS/MS (BRASIL, 2019) que: a) ratifica o não fechamento dos antigos Hospitais Psiquiátricos/Manicômios e reafirma seu financiamento, na contramão da proposição da $\mathrm{RPb}$; b) se posiciona favoravelmente ao retorno dos ambulatórios especializados, mesmo que eles tenham se mostrado obsoletos e produzam um aumento da medicalização da vida e do sofrimento; c) incentiva a prescrição do antigo e tão criticado eletrochoque em sua versão moderna, denominada eletroconvulsoterapia; d) na contramão da Política de Redução de Danos, fortalece o modelo das 
$\mathrm{CT}$, negligenciando o conjunto de denúncias e o relatório de inspeção realizado em parceria do Ministério Público com o Conselho Federal de Psicologia (CONSELHO FEDERAL DE PSICOLOGIA, 2019).

Tendo em vista que não existe previsão de aumento no orçamento para tais investimentos, o MS pode ter que realocar recursos de base territorial - como dos Caps e da Atenção Básica - para investir em hospitais e CT, comprometendo a manutenção daqueles estabelecimentos. Na Nota Técnica, existe o discurso de ineficiência da Raps, sem esclarecer que as dificuldades são oriundas justamente do sucateamento dos serviços por falta de investimentos e das últimas portarias que estão na contralógica da Atenção Psicossocial. Concordamos com Farias (2019, p. 59) ao pontuar que "fica explícito que os governantes estão interessados em repassar o dinheiro público para os empresários do setor psiquiátrico e terceiro setor filantrópicos, enriquecendo, dessa forma, a burguesia e outros setores conservadores [...]". Com essa nota técnica, ficou explícita a retomada do aumento da hegemonia do PPHM.

No apagar das luzes de 2020, o governo federal, por meio do MS sob influência da Associação Brasileira de Psiquiatria, planejou mudanças na PNSM que vinham junto com a revogação de portarias editadas entre 2001 e 2014, as quais sustentam o financiamento e o funcionamento da Raps. Essa revogação provocaria o desmonte na PNSM, impondo um grave retrocesso, um retorno à lógica manicomial. Em termos do PEH, constatase que estivemos vivenciando uma tentativa de aprofundamento de um processo de contrarreforma, com preponderância da restauração das concessões materializadas por meio das portarias publicadas.

Diante desse cenário sombrio, para resistir e enfrentar essa proposta, foi instituída a Frente Ampla em Defesa da Saúde Mental, da Reforma Psiquiátrica e da Luta Antimanicomial composta por trabalhadores, usuários e familiares, gestores da Raps, professores, universitários e parlamentares. Criou-se, também, uma agenda de mobilização e foram produzidos documentos, tais como a petição que reuniu aproximadamente $71 \mathrm{mil}$ assinaturas e os manifestos assinados por entidades, como, por exemplo, o Manifesto da Frente Ampla em Defesa da Saúde Mental, da Reforma Psiquiátrica e da Luta Antimanicomial. Por estarmos em meio a um processo de contrarreforma, de uma pura e simples restauração daquilo que foi concedido, o processo de luta pela $\mathrm{RPb}$ "[...] não se trava mais em nome da conquista de novos direitos, mas da defesa daqueles já conquistados no passado" (COUTINHO, 2012, p. 123). Por causa dessa mobilização em defesa da PNSM, o governo recuou do seu plano, ao menos temporariamente. 


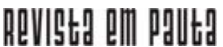

\} A POLÍTICA NACIONAL - MEXKO, S.; BENELLI, S. J.\}

DOI: $10.12957 /$ REP.2022.63480

\section{Considerações finais}

O breve percurso analítico sobre o processo de transformação da Atenção ao sofrimento psíquico possibilitou visualizar um conjunto de avanços na PNSM que foram possíveis a partir da luta pela conquista de uma outra hegemonia travada pelos movimentos pela Reforma Psiquiátrica em seu momento inicial. Esses avanços, enquanto concessões da classe dominante (operacionalizadas pelo Estado), contudo, ficaram aquém das demandas oriundas do próprio movimento, que pretendia a desinstitucionalização, a desconstrução do conceito de doença mental e propunha um novo modo de sociabilidade.

Apesar de a crítica social ao manicômio, enquanto estabelecimento institucional que visava ao lucro e à loucura como produto de uma sociedade organizada pelo MCP, ter sido um dos principais elementos constitutivos da $\mathrm{RPb}$, o fechamento dos grandes manicômios não foi realizado a partir de uma mudança social, uma vez que aconteceu de modo parcial e articulado com a expansão da indústria farmacêutica e com o alargamento do campo psiquiátrico - agora abrangendo todo o corpo social (GOTO, 2018). Ainda que a RPb tenha emergido da sociedade, em sua luta contra a manicomialização, opondo-se à supremacia do saber médico e em prol da construção de um novo modelo de Atenção em Saúde Mental, ela acabou por ser recuperada pelo MCP e implementada nos moldes da revolução passiva. No que diz respeito aos últimos anos, estamos vivendo um momento de intensas contrarreformas, o que nos coloca diante da necessidade de defender aquilo que ainda existe de conquista na Reforma Psiquiátrica antes mesmo de lutar por sua ampliação. 


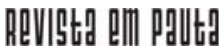

\} A POLÍTICA NACIONAL - MEXKO, S.; BENELLI, S. J. \}

DOI: $10.12957 /$ REP.2022.63480

\section{Referências}

ALTHUSSER. L. Ideologia e aparelhos ideológicos do Estado. Lisboa: Presença, 1980.

AMARANTE, P. D. C. (Coord.). Loucos pela vida: a trajetória da reforma psiquiátrica no Brasil. Rio de Janeiro: Fiocruz, 1998.

BAREMBLITT, G. F. Compêndio de análise institucional e outras correntes: teoria e prática. Belo Horizonte: Instituto Felix Guattari, 2012.

BIANCHI, A. Revolução passiva e crise de hegemonia no Brasil contemporâneo. Revista Outubro, v. 28, 2017.

BRASIL. Ministério da Saúde. Portaria n. 189, de 11 de dezembro de 1991. Dispõe sobre o atendimento à saúde mental no Brasil. Brasília, Diário Oficial da República Federativa do Brasil, 11 dez. 1991.

BRASIL. Ministério da Saúde. Portaria n. 224, de 29 de janeiro de 1992. Estabelece diretrizes e normas para o atendimento em saúde mental. Brasília, Diário Oficial da República Federativa do Brasil, 29 jan. 1992.

BRASIL. Ministério da Saúde. Portaria n. 106, 17 de junho de 2000. Dispõe sobre a criação e regulamentação das residências terapêuticas para portadores de transtornos mentais. Brasília, Diário Oficial da União, 2000.

BRASIL. Lei n. 10.216, de 6 de abril de 2001. Dispõe sobre a proteção e os direitos das pessoas portadoras de transtornos mentais e redireciona o modelo assistencial em saúde mental. Brasília, Diário Oficial Eletrônico, 9 abr. 2001.

BRASIL. Ministério da Saúde. Portaria n. 336/GM, de 19 de fevereiro de 2002. Saúde mental no SUS: os Centros de Atenção Psicossocial. Brasília: Ministério da Saúde, 2002.

BRASIL. Lei n. 10.708, de 31 de julho de 2003. Institui o auxílio-reabilitação psicossocial para pacientes acometidos de transtornos mentais egressos de internações. Brasília, Diário Oficial da União, 1 ago. 2003.

BRASIL. Conselho Nacional de Saúde. Relatório final da IV Conferência Nacional de Saúde Mental - Intersetorial. Brasília: Ministério da Saúde, 2010.

BRASIL. Ministério da Saúde. Portaria MS/GM n. 3.088, de 23 de dezembro de 2011. Institui a Rede de Atenção Psicossocial para pessoas com sofrimento ou transtorno mental e com necessidades decorrentes do uso de crack, álcool e outras drogas, no âmbito do Sistema Único de Saúde. Brasília, Diário Oficial da União, 2011.

BRASIL. Ministério da Saúde. Portaria MS/GM n. 131, de 26 de janeiro de 2012. Institui incentivo financeiro de custeio destinado aos estados, muni- 
cípios e ao Distrito Federal para apoio ao custeio de serviços de atenção em regime residencial, incluídas as comunidades terapêuticas, voltados para pessoas com necessidades decorrentes do uso de álcool, crack e outras drogas, no âmbito da Rede de Atenção Psicossocial. Brasília, Diário Oficial da União, 2012.

BRASIL. Resolução n. 32, de 14 de dezembro de 2017. Estabelece as diretrizes para o fortalecimento da Rede de Atenção Psicossocial (Raps). Brasília, Diário Oficial da União, 22 dez. 2017a.

BRASIL. Ministério da Saúde. Portaria n. 3.588, de 21 de dezembro de 2017. Altera as Portarias de Consolidação n. 3 e n. 6, de 28 de setembro de 2017, para dispor sobre a Rede de Atenção Psicossocial, e dá outras providências. Brasília, Diário Oficial da União, 2017b.

BRASIL. Portaria n. 2434, de 15 de agosto de 2018. Altera a Portaria de Consolidação n. 6/GM/MS, de 28 de setembro de 2017, para reajustar o valor das diárias de internação hospitalar acima de 90 (noventa) dias do incentivo para internação nos hospitais psiquiátricos. Brasília, Diário Oficial da União, 2018.

BRASIL. Ministério da Saúde. Secretaria de Atenção à Saúde. Nota técnica n. 11/2019-CGMAD/Dapes/SAS/MS. Esclarecimentos sobre as mudanças na política nacional de saúde mental e nas diretrizes da política nacional sobre drogas. Brasília: Ministério da Saúde, 2019.

CAPUTO, L. R. et al. A saúde mental em tempos de desafios e retrocessos: uma revisão. Argumentum, v. 12, n. 2, 2020.

CONSELHO FEDERAL DE PSICOLOGIA. Hospitais psiquiátricos no Brasil: relatório de inspeção nacional. Brasília: CFP, 2019.

COSTA-ROSA, A. Saúde Mental Comunitária: análise dialética das práticas alternativas. 1987. Dissertação (Mestrado em Psicologia) - Instituto de Psicologia, Universidade de São Paulo, São Paulo, 1987.

COSTA-ROSA, A. Atenção psicossocial além da Reforma Psiquiátrica: contribuição a uma clínica crítica dos processos de subjetivação na Saúde Coletiva. São Paulo: Unesp, 2013.

COUTINHO, C. N. A hegemonia da pequena política. In: OLIVEIRA, F.; BRAGA, R.; RIZEK, C. (Org.). Hegemonia às avessas: economia, política e cultura na era da servidão financeira. São Paulo: Boitempo, 2010.

COUTINHO, C. N. A época neoliberal: revolução passiva ou contrarreforma? Novos Rumos, Marília, v. 49, n. 1, p. 117-126, 2012.

FARIAS, L. L. Estado, contrarreforma e as política de saúde e saúde mental no Brasil. Argumentum, Vitória, v. 11, n. 3, set./dez. 2019. 


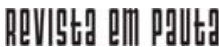

\} A POLÍTICA NACIONAL - MEXKO, S.; BENELLI, S. J.

DOI: $10.12957 /$ REP.2022.63480

GOTO, C. S. A reforma psiquiátrica no Brasil contemporâneo: ensaios da psicanálise lacaniana e da crítica da economia política. Dissertação (Mestrado em Psicologia e Sociedade) - Universidade Estadual Paulista "Júlio de Mesquita Filho", Assis, 2018.

GRUPPI, L. O conceito de hegemonia em Gramsci. Rio de Janeiro: Graal, 1978.

LOURAU, R. A análise institucional. Petrópolis: Vozes, 2014.

LUZ, M. T. As instituições médicas no Brasil: instituição e estratégia de hegemonia. Rio de Janeiro: Edições Graal, 1979.

MARQUES, R. M.; MENDES, Á. Servindo a dois senhores: as políticas sociais no governo Lula. Revista Katálysis, Florianópolis, v. 10, n. 1, jun. 2007.

OLIVEIRA, F. Hegemonia às avessas. In: OLIVEIRA, F.; BRAGA, R.; RIZEK, C. (Org.). Hegemonia às avessas: economia, política e cultura na era da servidão financeira. São Paulo: Boitempo, 2010.

PAIM, J. S. Modelos assistenciais: reformulando o pensamento e incorporando a proteção e a promoção da saúde. Brasília: ANVISA-UFBA, 2001. Disponível em: https://www.saude.rj.gov.br/comum/code/MostrarArquivo. php?C=MTIxNjE\%2C. Acesso em: 31 dez. 2020.

PITTA, A. M. F. Um balanço da reforma psiquiátrica brasileira: instituições, atores e políticas. Ciência e Saúde Coletiva, v. 16, n. 12, 2011.

SISTEMA ÚNICO DE SAÚDE. Conselho Nacional de Saúde. Relatório final da IV Conferência Nacional de Saúde Mental - Intersetorial. Brasília: Ministério da Saúde, 2010.

TEIXEIRA, C. F.; PAIM, J. S.; VILASBOAS, A. L. SUS, modelos assistenciais e vigilância da saúde. Inf. Epidemiol, Brasília, v. 7, n. 2, jun. 1998.

YASUI, S. Rupturas e encontros: desafios da reforma psiquiátrica brasileira. Tese (Doutorado em Ciências na Área de Saúde) - Escola Nacional de Saúde Pública Sérgio Arouca, Fundação Oswaldo Cruz, Fiocruz, Rio de Janeiro, 2006.

DOI: $10.12957 /$ rep.2022.63480

Recebido em 05 de julho de 2021.

Aprovado para publicação em 06 de outubro de 2021.

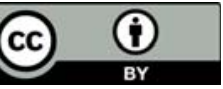

A Revista Em Pauta: Teoria Social e Realidade Contemporânea está licenciada com uma Licença Creative Commons Atribuição 4.0 Internacional. 